\title{
O ESTADO, A EDUCAÇÃO E A REGULAÇÃO DAS POLÍTICAS PÚBLICAS
}

JoÃo BARROSO

\begin{abstract}
RESUMO: O presente artigo tem como principal finalidade analisar e debater a evolução da intervenção do Estado na educação no quadro das transformaçôes que ocorrem, em diferentes países, na regulação das políticas e da acção públicas. Partindo da elucidação do conceito de regulação, apresento um modelo interpretativo para análise dos processos de regulação em educação, identificando, em seguida, as principais convergências e divergências que se verificam, em alguns países europeus, neste domínio, nomeadamente no que se refere à emergência de modelos de regulação pós-burocráticos. A parte final do artigo é consagrada à discussão do papel do Estado na defesa e promoção da escola pública, tendo em conta as evoluções que foram detectadas nos modos de governação e coordenação das políticas e da acção públicas em educação.
\end{abstract}

Palavras-chave: Regulação. Estado e mercado. Regulação pós-burocrática. Escola pública.

\section{STATE, EDUCATION AND REgULATION OF PUBliC POLICIES}

ABSTRACT: This paper mainly aims at analyzing and discussing the evolution of State interventions in Education within the framework of the on-going changes taking place in public action and policies in different countries. After clarifying the concept of regulation, it presents an interpretative model to analyze the regulation processes in Education. The main similarities and differences among some European countries are identified, namely the development of post-bureaucratic regulation models. The last section is devoted to discussing the State's role of protecting and promoting public education, considering the

Professor catedrático da Faculdade de Psicologia e de Ciências da Educação da Universidade de Lisboa. E-mail: jbarroso@fpce.ul.pt

Educ. Soc., Campinas, vol. 26, n. 92, p. 725-751, Especial - Out. 2005 
identified trends in the evolution of governance modes and in the coordination of public action and policies in Education.

Key words: Regulation. State and market. Post-bureaucratic regulation. Public education.

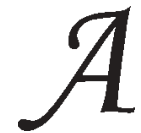

problemática da reforma e reestruturação do Estado constitui, principalmente a partir dos anos 80 do século XX, um tema central do debate político, num conjunto alargado de países, em todos os continentes, e está na origem de medidas políticas e legislativas, muito diversas, que afectaram a administração pública em geral e, consequentemente, a educação. É o caso, por exemplo: da descentralização; da autonomia das escolas; da livre escolha da escola pelos pais; do reforço de procedimentos de avaliação e prestação de contas; da diversificação da oferta escolar (cada "público" sua escola); da contratualização da gestão escolar e da prestação de determinados serviços; etc.

É no contexto deste debate que, na educação, se promovem, se discutem e se aplicam medidas políticas e administrativas que vão, em geral, no sentido de alterar os modos de regulação dos poderes públicos no sistema escolar (muitas vezes com recurso a dispositivos de mercado), ou de substituir esses poderes públicos por entidades privadas, em muitos dos domínios que constituíam, até aí, um campo privilegiado da intervenção do Estado. Estas medidas tanto podem obedecer (e serem justificadas), de um ponto de vista mais técnico, em função de critérios de modernização, desburocratização e combate à "ineficiência” do Estado ("new public management"), como serem justificadas por imperativos de natureza política, de acordo com projectos neoliberais e neoconservadores, com o fim de "libertar a sociedade civil" do controlo do Estado (privatização), ou mesmo de natureza filosófica e cultural (promover a participação comunitária, adaptar ao local) e de natureza pedagógica (centrar o ensino nos alunos e suas características específicas).

No presente artigo, irei analisar o sentido que estas e outras medidas tomaram à luz do conceito de regulação.

Numa primeira parte, irei explicitar o conceito de regulação e identificar os sentidos com que ele é usado, habitualmente, nos estudos internacionais sobre as políticas educativas.

Numa segunda parte, tomando como referência os resultados de um projecto de investigação sobre a emergência de novos modos de regulação 
das políticas educativas em cinco países europeus, irei apresentar uma breve síntese das principais transformações que ocorrem em Portugal e na Europa, bem como das principais convergências e divergências existentes neste domínio.

Numa terceira parte, procurarei retirar algumas ilaçóes sobre o sentido destas transformaçóes, questionando qual deve ser o papel do Estado na regulação da educação, nomeadamente no que se refere à manutenção do ideal da escola pública e ao seu compromisso com a distribuição equitativa do bem comum educativo.

\section{O conceito de regulação aplicado à educação}

A actual difusão, no domínio educativo, do termo "regulação" está associada, em geral, ao objectivo de consagrar, simbolicamente, um outro estatuto à intervenção do Estado na condução das políticas públicas. Muitas das referências que são feitas ao "novo" papel regulador do Estado servem para demarcar as propostas de "modernização" da administração pública das práticas tradicionais de controlo burocrático pelas normas e regulamentos que foram (e são ainda) apanágio da intervenção estatal. Neste sentido, a "regulação" (mais flexível na definição dos processos e rígida na avaliação da eficiência e eficácia dos resultados) seria o oposto da "regulamentação" (centrada na definição e controlo a priori dos procedimentos e relativamente indiferente às questôes da qualidade e eficácia dos resultados).

Apesar de amplamente divulgada, esta distinção não é rigorosa e não traduz quer o significado original do termo regulação, quer o sentido com que é utilizado na linguagem científica.

\section{A polissemia de um conceito}

Conforme definição consagrada nos dicionários, a regulação enquanto acto de regular significa o modo como se ajusta a acção (mecânica, biológica ou social) a determinadas finalidades, traduzidas sob a forma de regras e normas previamente definidas. Neste sentido, a diferença entre regulação e regulamentação não tem que ver com a sua finalidade (uma e outra visam a definição e cumprimento das regras que operacionalizam objectivos), mas com o facto de a regulamentação ser um caso 
particular de regulação, uma vez que as regras estão, neste caso, codificadas (fixadas) sob a forma de regulamentos, acabando, muitas vezes, por terem um valor em si mesmas, independente do seu uso.

Algumas acepções particulares ajudam a clarificar o uso corrente deste conceito. Por exemplo, na doutrina militar a regulação traduz "as operações que permitem, na utilização de material ou numa operação com tropa, o melhor resultado a melhor utilização e combinação dos esforços conjuntos, perante um objectivo, para o atingir nas melhores condiçōes e com o menor esforço" (Enciclopédia Portuguesa e Brasileira).

$\mathrm{O}$ conceito de regulação está igualmente associado ao controlo de elementos autónomos mas interdependentes e, neste sentido, é usado, por exemplo, em economia, para identificar a intervenção de instâncias com autoridade legítima (normalmente estatais) para orientarem e coordenarem a acção dos agentes económicos (a regulação dos preços, a regulação do comércio, da energia etc.).

Para lá destas acepções mais correntes, a elucidação do significado de regulação conheceu um notável incremento com o desenvolvimento da teoria dos sistemas. De um modo geral, a regulação é vista como uma função essencial para a manutenção do equilíbrio de qualquer sistema (físico ou social) e está associada aos processos de retroacção (positiva ou negativa). É ela que permite ao sistema, através dos seus órgãos reguladores, identificar as perturbações, analisar e tratar as informações relativas a um estado de desequilíbrio e transmitir um conjunto de ordens coerentes a um ou vários dos seus órgãos executores.

Se a regulação cibernética é vista como um conjunto de "reacções de reajustamento do equilíbrio do sistema" (Rosnay, 1975, p. 30), ela pode ser alargada, segundo alguns autores, ao próprio processo de transformação do sistema. É o que defende, por exemplo, Diebolt (2001) que, baseado na classificação hierárquica de níveis de regulação estabelecida por Piaget (1977, p. I-XIII), estabelece a distinção entre dois tipos de regulação complementares: as regulaçóes conservadoras e as regulaçóes transformadoras. No primeiro caso, "elas têm por única função assegurar a coerência, o equilíbrio e a reprodução idêntica do sistema” (p. 9). No segundo caso, elas desempenham uma tripla função: compreender como um sistema dá lugar a novas formas de organização; de que modo um processo de regulação dá origem ao seu sucessor; que interdependência se estabelece entre diferentes modos de regulação. Para Diebolt (2001, 
p. 10), que trabalha na área da economia da educação, a regulação define-se assim como: “(...) o conjunto de mecanismos que asseguram o desenvolvimento dum determinado sistema, através de um processo complexo de reprodução e transformação. Neste sentido, a regulação postula que a transformação de um sistema é a condição indispensável à manutenção da sua existência e coerência”.

O reconhecimento da existência, no interior do mesmo sistema, de vários dispositivos de regulação, com finalidades distintas, é igualmente proposta por Mehel (1974) que aplica a teoria dos sistemas à "análise científica dos fenómenos administrativo e educativo". Para este autor, nos sistemas complexos finalizados verifica-se uma "tripla regulação": uma pré-regulação e uma pós-regulação centralizadas e uma multi-regulação descentralizada que se pode chamar de co-regulação:

Nos regimes políticos centralizados, a pré-regulação estatal é privilegiada. Os regimes "burocráticos" correspondem a uma hipertrofia da pré-regulação. A desconcentração (desenvolvimento dos sub-transductores) e a descentralização (desenvolvimento dos sub-selectores) tendem a desenvolver a co-regulação. Por fim, os mecanismos de pós-regulação são ilustrados por medidas conjunturais, como a adaptação do plano em curso de execução, a função jurisdicional etc. (Mehel, 1974, p. 36).

\section{A regulação dos sistemas sociais}

Importa ter em atenção que, apesar do enorme potencial descritivo e explicativo que a abordagem sistémica trouxe à compreensão dos sistemas sociais, é preciso evitar uma transposição automática das leis da cibernética construídas sobre sistemas físicos e biológicos para os sistemas sociais. Crozier \& Friedberg (1977) que utilizam este tipo de abordagem para descrever a acção colectiva nas organizações (sistemas concretos de acção) advertem que o modelo subjacente à analogia cibernética é um modelo que ignora a dimensão estratégica, portanto, irredutivelmente imprevisível, do comportamento humano. Segundo estes autores, um sistema humano não obedece a regras precisas saídas de mecanismos automáticos de reajustamento, como acontece com os outros sistemas:

(...) nos sistemas humanos que chamamos de sistemas concretos de acção, a regulação não se opera, de facto, nem por sujeição a um órgão regulador, 
O estado, a educação e a regulação das políticas públicas

nem pelo exercício dum constrangimento mesmo que inconsciente, e muito menos por mecanismos automáticos de ajustamento mútuo, ela operase por mecanismo de jogos através dos quais os cálculos racionais "estratégicos" dos actores se encontram integrados em função de um modelo estruturado. Não são os homens que são regulados e estruturados, mas os jogos que lhes são oferecidos. (Crozier \& Friedberg, 1977, p. 244)

É este, igualmente, o sentido dado por Bauby (2002, p. 15) que, reportando-se aos sistemas sociais, define regulação como:

Modos de ajustamento permanentes de uma pluralidade de acções e seus efeitos que permitem assegurar o equilíbrio dinâmico de sistemas instáveis (...). A regulação resulta do facto de que as regras não podem prever tudo e por isso devem ser interpretadas, postas em causa (numa adaptação perpétua em função das situações e dos objectivos). A regulação de um grupo social corresponde, assim, às interacçôes entre os interesses particulares de cada componente do grupo e o interesse comum ou geral do mesmo.

Posição semelhante é defendida por Maroy \& Dupriez (2000) a propósito da regulação dos sistemas escolares. Estes autores consideram que, quando aplicada às organizações ou sistemas de acção organizada

a regulação é a resultante da articulação (ou da transacção) entre uma ou várias regulações de controlo e processos "horizontais" de produção de normas na organização. A regulação é entendida no sentido activo de processo social de produção de "regras de jogo" permitindo resolver problemas de interdependência e de coordenação. (Maroy \& Dupriez, op. cit., p. 76)

Se tomarmos em consideração os trabalhos de Reynaud (1997 e 2003) é possível identificar três dimensões complementares do processo de regulação dos sistemas sociais: a regulação institucional, normativa e de controlo; a regulação situacional, activa e autónoma; e a "regulação conjunta".

No primeiro caso, a regulação pode ser definida como "o conjunto de acções decididas e executadas por uma instância (governo, hierarquia de uma organização) para orientar as acções e as interacçōes dos actores sobre os quais detém uma certa autoridade" (Maroy e Dupriez, 2000). Esta definição põe em evidência, no conceito de regulação, as dimensões de coordenação, controlo e influência exercidas pelos detentores de uma autoridade legítima, sendo por isso próxima da acepção que prevalece na literatura americana (no domínio da economia, mas também da educa- 
ção) enquanto intervenção das autoridades públicas para introduzir "regras" e "constrangimentos" no mercado ou na acção social.

No segundo caso, a regulação é vista, sobretudo, como um processo activo de produção de "regras de jogo" (Reynaud, 1997) que compreende não só a definição de regras (normas, injunções, constrangimentos etc.) que orientam o funcionamento do sistema, mas também o seu (re)ajustamento provocado pela diversidade de estratégias e acções dos vários actores, em função dessas mesmas regras. De acordo com esta abordagem, num sistema social complexo (como é o sistema educativo) existe uma pluralidade de fontes, de finalidades e modalidades de regulação, em função da diversidade dos actores envolvidos, das suas posições, dos seus interesses e estratégias (Barroso, 2000).

No terceiro caso, a "regulação conjunta" significa a interacção entre a regulação de controlo e a regulação autônoma, tendo em vista a produção de regras comuns (Reynaud, 2003).

Idêntica distinção é feita por Dubet, que fala de "regulação normativa" (produção de normas pelo Estado, tendo em vista mudanças voluntárias através da interiorização e socialização dessas mesmas normas pelos indivíduos) e "regulação sistémica" (processo pelo qual o sistema social se reproduz e transforma, através de efeitos não necessariamente intencionais, como por exemplo efeitos de composição). ${ }^{1}$ De referir, finalmente, que, como afirma Bettencourt (2004, p. 53):

Nas ciências sociais, as teorias não conflituais, vêem no ajustamento [entre os diferentes actores envolvidos no processo de regulação] a procura de um equilíbrio social óptimo. Elas reforçam a ideia corrente de regulação como a obtenção de um funcionamento "correcto". Pelo contrário, segundo as abordagens políticas, a regulação não assegura nem a harmonia, nem a estabilização rigorosa, nem a optimização, porque a elaboração e a aplicação das regras é uma disputa social e dá lugar a conflitos, quer abertos e violentos, quer instituídos quer escondidos.

\section{Contextos linguísticos}

Além desta diversidade de acepções, aqui brevemente sumariada, é importante ter em conta que a utilização do termo "regulação" nos estudos internacionais sobre políticas educativas varia muito conforme os contextos linguístico e administrativo dominantes. 
Num primeiro contexto, a ocorrência do termo regulação aparece principalmente associada ao debate sobre a reforma da administração do Estado na educação e sua modernização. Isto acontece, sobretudo, num contexto linguístico francófono e em países onde ainda predomina uma administração muito centralizada e burocratizada. A referência à "regulação" aparece como resultado de um certo efeito de moda (ou aggiornamento linguístico), com o fim de reforçar a imagem de um Estado menos prescritivo e regulamentador e de uma "nova administração pública" que substitui um controlo directo e a priori sobre os processos, por um controlo remoto, e a posteriori baseado nos resultados. A referência a um "Estado regulador" pressupõe, nesta perspectiva, o reconhecimento e a existência de unidades autónomas no sistema e é utilizada como expressão de uma certa modernização da administração da educação pública que evolui, como sublinha Demailly (2001) falando do caso francês, de um quadro normativo baseado na "obrigação de meios" para um outro, baseado na "obrigação de resultados". Um exemplo típico desta utilização do conceito de "regulação" encontra-se na citação seguinte retirada das conclusões de um estudo sobre as tendências evolutivas das políticas educativas no Canadá, Estados Unidos, França e Reino Unido (Lessard, Brassard \& Lusignan, 2002, p. 35):

O Estado não se retira da educação. Ele adopta um novo papel, o do Estado regulador e avaliador que define as grandes orientações e os alvos a atingir, ao mesmo tempo que monta um sistema de monitorização e de avaliação para saber se os resultados desejados foram, ou não, alcançados. Se, por um lado, ele continua a investir uma parte considerável do seu orçamento em educação, por outro, ele abandona parcialmente a organização e a gestão quotidiana, funções que transfere para os níveis intermediários e locais, em parceria e concorrência com actores privados desejosos de assumirem uma parte significativa do "mercado" educativo.

Num segundo contexto, a ocorrência do termo regulação aparece predominantemente associada, por oposição, ao conceito de "desregulação". Neste caso, a oposição regulação/desregulação, pretende sublinhar uma ruptura com os modelos "tradicionais" de intervenção do Estado na coordenação e pilotagem do sistema público de educação. Isto ocorre sobretudo num contexto linguístico anglo-saxónico e, principalmente, em países, onde se verificaram mudanças políticas de cariz conservador e neoliberal. Nestes países o que está em causa não é uma simples alteração dos modos de regulação pelo Estado, mas a substituiçãa parcial da 
regulação estatal por uma regulação de iniciativa privada através da criação de quase-mercados educacionais. Trata-se, como escreve Gintis (1995), de substituir um "governo apostado na produção directa de bens e serviços", por um governo que visa, preferencialmente, a regulação da produção e da distribuição desses bens e serviços, que são fornecidos, no quadro de um sistema competitivo, por outras entidades. Como afirma o mesmo autor, "o uso do mercado tem, neste contexto, um sentido mais instrumental, do que alternativo a um processo de decisão democrática" (p. 19). Neste sentido, a "regulação" (entendida como a intervenção das autoridades governamentais na prestação de um serviço público) é vista como um "movimento" oposto à "privatização" (entendida como a transferência para autoridades não-governamentais, com fins ou sem fins lucrativos, do controlo e prestação desses mesmos serviços).

\section{Um modelo interpretativo}

Tendo em conta a revisão que fiz sobre a pluralidade de significados que o conceito de regulação adquire conforme os contextos disciplinares e linguísticos, importa, agora, sistematizar de um ponto de vista mais interpretativo em que consiste a regulação enquanto modo de coordenação dos sistemas educativos (ver, a este propósito, Barroso, 2005):

- A regulação é um processo constitutivo de qualquer sistema e tem por principal função assegurar o equilíbrio, a coerência, mas também a transformação desse mesmo sistema.

- O processo de regulação compreende, não só, a produção de regras (normas, injunções, constrangimentos etc.) que orientam o funcionamento do sistema, mas também o (re) ajustamento da diversidade de acções dos actores em função dessas mesmas regras.

- Num sistema social complexo (como é o sistema educativo) existe uma pluralidade de fontes (centro/periferia, interno/externo, actor A/actor B etc.), de finalidades e modalidades de regulação, em função da diversidade dos actores envolvidos, das suas posições, dos seus interesses e estratégias.

- A regulação do sistema educativo não é um processo único, automático e previsível, mas sim um processo compósito que 
resulta mais da regulação das regulações, do que do controlo directo da aplicação de uma regra sobre acção dos "regulados".

- Embora no quadro do sistema público de ensino o Estado constitua uma fonte essencial de regulação, ele não é a única, nem por vezes a mais decisiva nos resultados finais obtidos. Nesse sentido, não parecem inteiramente adequados os comentários produzidos por muitos autores, oriundos da sociologia crítica, quando afirmam que vivemos um período de "des-regulação" do sistema educativo, ou como defende Ball (2001), de simples "re-regulação". Na verdade, essa é uma visão parcial do processo que ignora as múltiplas regulações (por vezes contraditórias) a que o sistema está sujeito (por parte dos professores, dos pais, da comunicação social, e de outros agentes sociais) e que torna imprevisível o efeito das regulações institucionais desencadeadas pelo Estado e sua administração.

- A diversidade de fontes e modos de regulação faz com que a coordenação, equilíbrio ou transformação do funcionamento do sistema educativo resultem mais da interacção dos vários dispositivos reguladores do que da aplicação linear de normas, regras e orientaçōes oriundas do poder político. Por isso, mais do que falar de regulação seria melhor falar de "multi-regulação", já que as acçôes que garantem o funcionamento do sistema educativo são determinadas por um feixe de dispositivos reguladores que muitas vezes se anulam entre si, ou pelo menos, relativizam a relação causal entre princípios, objectivos, processos e resultados. Os ajustamentos e reajustamentos a que estes processos de regulação dão lugar não resultam de um qualquer imperativo (político, ideológico, ético) definido a priori, mas sim dos interesses, estratégias e lógicas de acção de diferentes grupos de actores, por meio de processos de confrontação, negociação e recomposição de objectivos e poderes.

- Se entendermos a "regulação do sistema educativo" como um "sistema de regulaçōes" torna-se necessário valorizar, no funcionamento desse sistema, o papel fundamental das instâncias (indivíduos, estruturas formais ou informais) de mediação, tradução, passagem dos vários fluxos reguladores, uma vez que é aí 
que se faz a síntese ou se superam os conflitos entre as várias regulaçôes existentes. Estas instâncias funcionam como uma espécie de "nós da rede" de diferentes reguladores e a sua intervenção é decisiva para a configuração da estrutura e dinâmica do sistema de regulação e seus resultados.

- Esta verificação da complexidade dos processos de regulação do funcionamento do sistema educativo, bem como da dificuldade de prever (e orientar) com um mínimo de segurança e de certeza a direcção que ele vai tomar, tornam bastante improvável o sucesso de qualquer estratégia de transformação baseada num processo normativo de mudança, como são as reformas. De registar ainda que essa improbabilidade é tanto maior quanto não existe hoje qualquer consenso quanto aos princípios e normas (no sentido lato) que devem orientar o funcionamento do sistema, nem a sua transformação.

- Como é evidente, a multiplicidade de processos de regulação e a sua difícil compatibilização tornam não só problemáticas as próprias noçōes de "equilíbrio" e "coerência", intrínsecas a qualquer sistema, como põem em causa a própria possibilidade de existência de "um sistema nacional" de ensino. A tentativa de superar esta situação está na origem de diferentes propostas ou medidas de política educativa, que se podem consubstanciar nas seguintes modalidades (de natureza e propósitos políticos diferentes): segmentação do sistema nacional de ensino em subsistemas locais relativamente independentes; substituição da regulação das estruturas e dos processos pela auto-regulação das pessoas; construção de acordos ou compromissos sobre a natureza e finalidades do bem comum educativo, que permitam a convergência dos diversos processos de regulação.

Os novos modos de regulação das políticas educativas

Como já foi referido, assistimos hoje a uma transformação profunda no modo como é entendida e posta em prática a regulação das políticas educativas, no contexto de uma alteração mais ampla relacionada com a própria concepção, reforma e reestruturação do Estado e da sua administração (Barroso, 2003a, 2004b e 2005). 
Nesta secção irei apresentar, de modo muito sumário, as principais conclusões de um projecto europeu de investigação (cuja equipa portuguesa coordenei) e que teve como principal objectivo realizar um estudo comparado sobre a emergência de novos modos de regulação das políticas educativas e a sua relação com os processos de produção local de desigualdades e de segregação escolares.

Este projecto, intitulado Changes in regulation modes and social production of inequalities in educational systems: a European comparison e designado pelo acrónimo Reguleducnetwork, decorreu entre Outubro de 2001 e Outubro de 2004 e abrangeu cinco países europeus: Bélgica (francófona), França, Hungria, Portugal e Reino Unido (só a Inglaterra e País de Gales). ${ }^{2}$

Os trabalhos de investigação incidiram, progressivamente, na descrição e análise dos diferentes modos de regulação dos sistemas educativos dos países envolvidos, em três níveis: nível nacional, centrando o estudo na regulação de carácter institucional; nível intermédio, incidindo sobre as instâncias de regulação que operam em territórios intermédios do sistema educativo (entre o nacional e o local); e, finalmente, o nível local, que se refere ao estudo dos modos de regulação interna das escolas.

\section{Convergências e divergências}

Os estudos realizados, primeiro em cada país e depois numa perspectiva comparada, permitiram identificar um conjunto de convergências significativas na emergência de novos modos de regulação das políticas educativas, ainda que essas convergências se traduzissem, por vezes, em políticas não totalmente coincidentes ou até, mesmo, divergentes. ${ }^{3}$ De um modo esquemático, podemos resumir as principais conclusões sobre esta matéria nos seguintes pontos:

- Apesar de diferenças importantes nas características dos seus sistemas escolares e modos de coordenação, os cinco países estudados tiveram, até à década de 80 do século passado, um modelo de regulação das políticas educativas comum. Esse modelo, designado por burocrático-profissional, baseava-se numa "aliança" entre o Estado e os professores, combinado uma regulação "estatal, burocrática e administrativa" 
com uma regulação "profissional, corporativa e pedagógica" (ver, a este propósito, Barroso, 2000 e 2002).

- As políticas actuais caracterizam-se por uma oposição a este modelo burocrático-profissional e convergem parcialmente em trajectórias que tendem a impulsionar modelos de governança e de regulação que se podem designar por pósburocráticos. Estes modelos organizam-se em torno de dois referenciais principais: o do "Estado avaliador" e o do "quase-mercado".

- Contudo, estas convergências parciais nos modelos de referência não implicam, necessariamente, políticas totalmente idênticas. Por um lado, porque as políticas se referem a estes modelos em proporções diferentes; por outro, porque estas políticas se desenvolvem a partir de contextos de partida diferentes.

A figura 1 apresenta uma síntese das principais convergências detectadas e que vão no sentido da construção de um modelo pós-burocrático de regulaçãa.

Figura 1

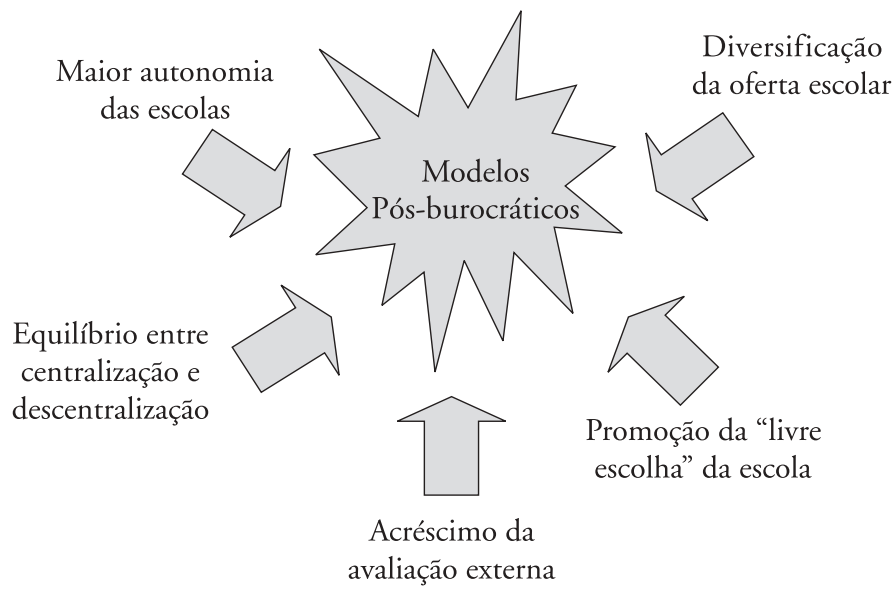

Estas convergências resultam de diversos factores, em particular: o desenvolvimento da globalização económica e do pós-fordismo; crise da 
legitimidade e da racionalidade do Estado Providência e emergência de referenciais políticos neoliberais; procura crescente por parte de diferentes grupos sociais de percursos educativos individualizados e de possibilidade de escolha para a escolarização dos seus filhos; contaminação e externalização das políticas nacionais (Afonso, 2003; Barroso, 2003c).

Apesar desta convergência em direcção a um modelo de regulação pós-burocrática, verifica-se que na realidade dos sistemas escolares dos países estudados se encontram diferentes cambiantes deste processo (visíveis sobretudo na investigação realizada em unidades específicas ao nível intermédio ou local), conforme se sintetiza na figura 2 .

Figura 2

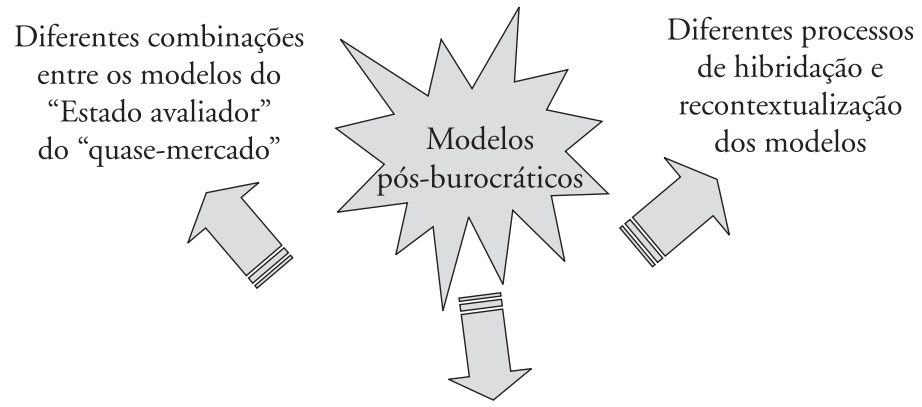

Diferentes composiçóes "mosaico" como resultado da sedimentação legislativa e das lógicas políticas aditivas

Estas divergências resultam, sobretudo, dos diferentes contextos de partida em cada país (político, económico, histórico etc.); da hibridação dos novos modos de regulação com a situação existente; dos processos de sedimentação legislativa e das lógicas políticas aditivas.

\section{Algumas especificidades nacionais}

As tendências assinaladas na figura 1 (convergências) abrangem, como vimos, o conjunto dos cinco países em estudo, embora com especificidades que decorrem dos diferentes contextos nacionais. Assim, por exemplo, em Portugal e na França as transformações processam-se mais lentamente e de maneira menos radical. Em contrapartida, na Inglaterra e na Bélgica (francófona) a evolução para modelos de regulação 
pós-burocráticos é mais acentuada, encontrando-se a Hungria numa posição intermédia. De registar ainda que a situação específica de Portugal e da França se fica a dever, em certa medida, à importância que continua a ter, nestes países, o referencial tradicional da "escola pública" e ao peso que a administração central preserva na estrutura do poder do Estado.

Do mesmo modo, no que se refere à tentativa de equilíbrio centralização/descentralização, verifica-se que nos países de tradição centralista (França, Hungria, Portugal) a evolução faz-se no sentido de aumentar o poder de decisão ao nível intermédio ou local, ao passo que na Inglaterra e Bélgica francófona (países tradicionalmente descentralizados) se assiste, principalmente no primeiro caso, a um reforço dos mecanismos de controlo centrais (sobretudo ao nível do currículo e da avaliação) e à perda de influência das autoridades municipais.

A França e a Inglaterra são os países onde os processos de avaliação externa das escolas e do sistema estão mais desenvolvidos e são mais sofisticados. Contudo, no primeiro caso, isso é feito por meio de um departamento central do Ministério da Educação (DEP) e, no caso inglês, por meio de uma agência nacional independente (OFSTED). E também na Inglaterra, onde os efeitos da avaliação têm mais incidência no funcionamento das escolas (que podem encerrar ou serem sujeitas a programas especiais de reconversão). Ao passo que nos outros países, incluindo a França, a incidência da avaliação como mecanismo de correcção é muito menor e, por vezes, tem um efeito meramente simbólico.

Quanto à "livre escolha" da escola pelos pais, ela é praticada desde há muito na Bélgica francófona (originariamente por motivos religiosos) e tem vindo a aumentar grandemente na Inglaterra por meio de uma política estatal voluntarista de criação de um "quase-mercado" escolar. Em França e em Portugal ainda subsiste a "carta escolar" (com obrigação de frequência da escola em função do local de residência), mas ela é atenuada na prática, devido à pressão de pais oriundos da classe média, que aproveitam a baixa demográfica e a maior disponibilidade da oferta para desenvolverem estratégias de individualização dos percursos escolares dos seus filhos (ver, a este propósito, Barroso \& Viseu, 2003). De registar, contudo, que nestes dois países o abrandamento dos critérios de "sectorização" escolar parece não pôr em causa uma vontade política de preservar a natureza igualitária da oferta educativa. Na Hungria coexistem os dois sistemas com uma clara elitização do sistema de escolha, que privilegia grupos sociais mais favorecidos. 
O estado, a educação e a regulação das políticas públicas

\section{Em síntese}

Como é assinalado no Relatório Final do Projecto Reguleducnetwork (Maroy, 2004), as políticas educativas dos cinco países estudados inspiram-se de um modo geral nos modelos pós-burocráticos, em particular do "Estado avaliador". Contudo, o grau de intensidade das políticas postas em prática e a dosagem entre os diversos modelos são muito variados.

A situação mais radical encontra-se na Inglaterra, onde se verifica uma política voluntarista de criação de um "quase-mercado" educativo. O controlo central e a lógica mercantil reforçaram-se em detrimento da capacidade de intervenção das autoridades locais. Neste país, a partir do início dos anos 80 do século passado, por iniciativa dos governos conservadores, retomada pelos governos trabalhistas, o poder central desenvolveu uma política substancial de intervencionismo incitando a competição entre as escolas e favorecendo a "livre escolha" pelos pais, nomeadamente por meio do alargamento dos dispositivos de avaliação externa e maior informação dos resultados às famílias.

Os outros países conhecem evoluções menos radicais e menos dependentes de políticas voluntaristas. Eles são também menos influenciados pelo modelo do "quase-mercado". A avaliação externa é embrionária ou sem consequências e a escolha da escola é mais tolerada do que promovida. Apesar de prevalecer uma política oficial que privilegia a "modernização" da administração escolar sem pôr em causa os valores da igualdade de oportunidades, o certo é que muitas das medidas tomadas favorecem a introdução de uma lógica de mercado na prestação do serviço educativo, cujos efeitos contrariam claramente esses princípios. Além disso, a crítica ao centralismo, à burocracia e ao défice de qualidade dos serviços públicos é aproveitada pelos defensores das políticas neoliberais para reclamarem a diminuição da intervenção do Estado e a privatização da prestação do serviço educativo, como única solução para os problemas com que se debate actualmente a escola pública.

\section{Da crise do estado à defesa da escola pública}

O século XX foi dominado, como refere Fukuyama (2004), por uma controvérsia política permanente em torno das questóes da natureza, poder, dimensão e campo de acção do Estado. Iniciou-se sob os auspícios do "liberalismo" britânico (com a ausência quase total da inter- 
venção do Estado). Em seguida, principalmente após a Segunda Guerra Mundial, assistiu-se a um crescente aumento do poder e intervenção do Estado (quer sob a forma perversa dos totalitarismos, quer sob a forma protectora e desenvolvimentista do Estado Providência). Finalmente, a partir dos anos de 1980, através do tatcherismo e do regganismo, assistiu-se ao surgimento das chamadas "políticas neoliberais" (com a redução do papel do Estado e a criação de mercados, ou quase-mercados, nos sectores tradicionalmente públicos - saúde, educação, transportes etc.). Estas "políticas neoliberais" afectaram directamente muitos outros países e foram adoptadas como referenciais para os programas de desenvolvimento conduzidos pelas grandes organizações internacionais (FMI, Banco Mundial, OCDE etc.) no que foi designado por "consenso de Washington", cujas principais "receitas" passavam por: disciplina orçamental, reforma fiscal, eliminação das barreiras às trocas internacionais, privatização e desregulamentação, com o consequente apagamento da intervenção do Estado. Com o virar do milênio, assiste-se a um recuo das teorias mais radicais do neoliberalismo e à emergência de propostas alternativas que vão no sentido de procurar um equilíbrio entre o "Estado" e o "mercado", ou mesmo no sentido de superar esta dicotomia pela reactivação de formas de intervenção sócio-comunitária na gestão da coisa pública.

\section{O neoliberalismo educativo}

No domínio da educação, a influência das ideias neoliberais fez-se sentir quer por meio de múltiplas reformas estruturais, de dimensão e amplitude diferentes, destinadas a reduzir a intervenção do Estado na provisão e administração do serviço educativo, quer por meio de retóricas discursivas (dos políticos, dos peritos, dos meios de informação) de crítica ao serviço público estatal e de "encorajamento do mercado".

Este "encorajamento do mercado" traduz-se, sobretudo, na subordinação das políticas de educação a uma lógica estritamente económica ("globalização"); na importação de valores (competição, concorrência, excelência etc.) e modelos de gestão empresarial, como referentes para a "modernização" do serviço público de educação; na promoção de medidas tendentes à sua privatização.

Como afirma Nóvoa (1998, p. 108), falando das "racionalidades" do discurso educativo da Comissão Europeia, na década de 1990: 
A racionalidade económica acompanha-se duma orientação neoliberal que serve de enquadramento ao discurso da privatização, da liberdade de escolha e mesmo da participação. No livro branco "Crescimento, competitividade e emprego" defende-se a necessidade duma maior implicação do sector privado nos sistemas de educação e/ou formação profissional e na formulação das políticas de educação para ter em conta as necessidades do mercado de trabalho e as circunstâncias locais.

Assiste-se, por isso, à tentativa de criar mercados (ou quase-mercados) educativos transformando a ideia de "serviço público" em "serviços para clientes", onde o "bem comum educativo" para todos é substituído por "bens" diversos, desigualmente acessíveis. Sob a aparência de um mercado único, funcionam diferentes submercados onde os "consumidores" de educação e formação, socialmente diferenciados, vêm-lhes serem propostos produtos de natureza e qualidade desiguais. Para estimular a criação destes mercados, o financiamento da educação (mesmo se à custa do erário público) é dirigido às famílias pelo sistema de "vouchers", ou equivalente, e procede-se à privatização parcial ou total da propriedade ou da gestão das escolas (ver, a este propósito, Barroso, 2003b). O objectivo central já não é adequar a educação e o emprego, mas articular o "mercado da educação" com o "mercado de emprego", nem que para isso seja necessário criar um "mercado dos excluídos" (para utilizar a expressão de Dominique Glassman).

Neste contexto de incertezas, os critérios e opções de financiamento deixam de ser objecto de uma planificação que traduza escolhas políticas definidas pelo Estado e passam a ser confiados à "mão invisível" do mercado em função de objectivos de eficácia, qualidade e excelência definidos de maneira unívoca pelas regras da concorrência. Depois do "tudo Estado" passou-se para o "tudo mercado"! Como dizem Tyack \& Cuban (1995, p. 142) a propósito da situação existente nos Estados Unidos:

Nesta última geração, o discurso sobre a escola pública tornou-se extremamente limitado. Passou a estar centrado na competição económica internacional, nos resultados dos testes, e na "escolha" individual da escola. Mas, em contrapartida, negligenciou por completo o tipo de escolhas que são essenciais para o bem-estar cívico: escolhas colectivas sobre um futuro comum, escolhas feitas, através de processos democráticos, sobre os valores e os conhecimentos que os cidadãos querem passar para a próxima geração. 


\section{A crise do modelo neoliberal}

Com o início do século XXI, a euforia "neoliberal" dos anos de 1980 e princípios dos anos de 1990 parece estar a empalidecer mesmo entre os seus defensores e promotores, nomeadamente no seio das grandes organizações internacionais (Banco Mundial, OCDE etc.). As receitas do "consenso de Washington" começam a ser postas em causa com as experiências dolorosas dos países europeus do "antigo bloco de leste" ou dos "tigres" asiáticos ou das "economias emergentes” da América Latina. É neste contexto que se começa a assistir a uma redefinição das relações entre economia e política no quadro dos processos de desenvolvimento em geral.

Como afirma a este propósito Boyer (2001, p. 49-50), fazendo uma síntese do que considera ser um modelo emergente no início do século XXI para superar a "crise do consenso de Washington" e a dicotomia Estado/mercado, de acordo com o que chama de uma "concepção de desenvolvimento fundada na inovação institucional":

Por um lado, sabemos hoje, o sucesso do desenvolvimento resulta da complementaridade destas duas lógicas [estado/mercado] e não, na afirmação de uma delas. É preciso lembrar que o mercado é uma construção social cuja emergência e viabilidade supóem um conjunto rico e complexo de regras jurídicas, códigos e autoridades encarregadas do seu bom funcionamento. Por outro lado, as investigações institucionalistas contemporâneas sublinham que formas institucionais intermédias entre o Estado e o mercado, como as associaçóes, as comunidades, os partenariados, (...) podem desempenhar um papel determinante na conciliação dos imperativos de eficácia dinâmica, isto é, um crescimento da produtividade e do nível de vida, com os imperativos de justiça social, na ocorrência uma repartição não excessivamente desigual dos dividendos do crescimento.

No mesmo sentido parece ir a Comissão Europeia quando procura definir e regulamentar aquilo que designa por "serviços de interesse geral' e que visa "atingir objectivos de serviço público no seio de mercados abertos e concorrenciais” (Livro Branco). Estes serviços abrangem serviços de interesse económico e não-económico (energia, serviços postais, transportes e telecomunicações, saúde, educação, serviço sociais) e a este propósito pode ler-se no "Livro Verde sobre os Serviços Gerais" (Comissão das Comunidades Europeias, 2003, p. 3), que esteve recentemente em discussão: 
Os serviços de interesse geral encontram-se no cerne do debate político. Com efeito, eles dizem respeito à questão central do papel desempenhado pelas autoridades públicas numa economia de mercado, a saber: por um lado, vigiar pelo bom funcionamento do mercado e pelo respeito das regras de jogo por todos os actores; por outro, garantir o interesse geral, especialmente no que se refere à satisfação das necessidades essenciais dos cidadãos e a preservação dos bens públicos no caso em que o mercado é incapaz de o fazer.

Este movimento contra os "excessos de liberalismo" e a favor da necessidade de preservar a existência de um Estado forte (ainda que com um campo de acção mais limitado) surge igualmente entre os defensores das posições mais ortodoxas do "consenso de Washington", como é o caso de Francis Fukuyama (principalmente conhecido no início dos anos de 1990 pelo seu livro O fim da história) e que agora (em 2004, p. 23) escreve num livro sugestivamente chamado State building - governance and world order:

(...) se é certo que era preciso reduzir o peso do Estado em certos domínios [como propunha o "consenso de Washington"], era preciso, ao mesmo tempo, reforçá-lo em outros. Os economistas que defenderam as reformas liberais compreendiam isto em teoria, mas a tónica foi posta, neste período, na redução das actividades do Estado, o que se podia confundir facilmente (ou ser voluntariamente mal interpretado) com um esforço para reduzir as capacidades e as competências do Estado. Deste modo, foi descurada a reflexão e a atenção ao programa de "construção do Estado" (state building) que era, pelo menos, tão importante como o programa que visava a sua redução. O resultado foi que a reforma económica de tendência liberal fracassou na concretização das suas promessas, em inúmeros países. Em alguns deles, a ausência de um quadro institucional apropriado pô-los numa situação ainda pior do que antes da "liberalização".

Importa, ainda, assinalar que, para além deste recuo dos defensores do neoliberalismo (perante o insucesso das suas receitas) e da tentativa de encontrar a "justa medida" entre Estado e mercado como estas tendências indiciam, há os que defendem (como eu tenho feito desde há muito, na educação) que não podemos ficar prisioneiros da falsa dicotomia entre estes dois modelos. Por isso, é preciso revitalizar outras modalidades de regulação da acção pública. Como diz Whitty (2002, p. 20) a este propósito: 
(...) nem o Estado, nem a sociedade civil constituem um contexto adequado para o exercício de uma cidadania activa e democrática, através da qual seja alcançada a justiça social. A reafirmação dos direitos dos cidadãos em educação parece exigir o desenvolvimento de uma nova esfera pública, algures entre o Estado e a sociedade civil mercantilizada, em que novas formas de associação colectiva possam ser desenvolvidas. O desafio reside em saber como sair de um processo de decisão atomizado, para o assumir de uma responsabilidade colectiva em educação, mas sem recriar um sistema de planificação supercentralizado (...).

\section{Defender e promover a escola pública}

Como se vê, estamos em pleno processo de recomposição das relações entre Estado e mercado, no que se refere ao fornecimento e financiamento dos serviços públicos, incluindo, no caso vertente, a educação. Contudo, por muito estimulantes que sejam as teorias e as estratégias da complementaridade dos modelos e da variedade de situações em que podem ser aplicados, é importante não esquecer que, para lá das soluções técnicas, há sempre que saber colocar as questōes políticas. Isso obriga, como afirma Rui Canário (2002, p. 150), a "pensar a escola a partir de um projecto de sociedade" e, para isso, precisamos aprender a pensar ao contrário do que a "vulgata" economicista recomenda, ou seja, "pensar a partir não dos meios disponíveis, mas das finalidades a atingir" (idem, ibid., p. 151), ou como recomenda Paulo Freire a "problematizar o futuro" sem o considerar como "inexorável".

É por isso que, independentemente da alteração das formas de regulação e da variação do peso relativo dos vários níveis e actores, qualquer mudança neste domínio não pode ser vista independentemente de um projecto político nacional que, neste caso, tem de passar pela promoção e defesa dos princípios fundadores da "escola pública" (enquanto garantia da aquisição e distribuição equitativa de um bem comum educativo).

Entre esses princípios quero destacar: a universalidade do acesso, a igualdade de oportunidades e a continuidade dos percursos escolares. Estes princípios obrigam a que escola seja sábia para educar (permitindo a emancipação pelo saber), recta para integrar as crianças e os jovens na vida social (por meio da partilha de uma cultura comum) e justa (participando na função social de distribuição de competências). 
É certo que, em muitos casos, estes princípios não tiveram correspondência nas políticas, nas formas de organização, no currículo e nos métodos pedagógicos, em que assenta a escola de massas, ao longo da sua evolução histórica e no seu processo de expansão à escala planetária. Contudo, há que reconhecer, o desenvolvimento da humanidade, principalmente neste último século, ficou a dever muito à expansão da escola pública, e a sua crise actual não deve servir para negar a validade dos seus princípios e do ideal de educação que lhes estão subjacentes, nem justifica o recurso ao modelo do mercado como alternativa para a regulação e provisão do serviço público educativo.

Por um lado, falta ao mercado (entre outras coisas) a sensibilidade social que permita atender aos que, pelas mais diversas razões, exigem mais tempo, mais dinheiro e melhores recursos para obterem o sucesso educativo a que têm direito. Por outro, o Estado social não pode estar limitado (como querem os defensores de políticas neoliberais neste domínio) a cumprir as funções de "carro-vassoura" dos excluídos que o mercado enjeita (por questôes de rentabilidade e eficácia). E, aqui, o recurso à metáfora do "carro-vassoura" justifica-se plenamente se nos recordarmos que esta designação é dada, nas corridas de ciclismo, ao carro que vai na cauda do pelotão para recolher os ciclistas que são obrigados a desistir, por não conseguirem acompanhar o andamento dos outros corredores.

Defendo por isso que, no contexto actual da crise do Estado Providência (e do modelo social a que deu origem), se torna necessário reforçar a dimensão pública da escola pública, o que obriga a reafirmar os seus valores fundadores, perante a difusão transnacional de uma vulgata neoliberal que vê no serviço público a origem de todos os males da educação e na sua privatização a única alternativa (Barroso, 2004a).

Mas defendo, igualmente, que a falência actual do modelo de regulação burocrático-profissional, que serviu de base à expansão da escola pública no passado, obriga a procurar novas formas organizativas (pedagógicas e educativas) e novas modalidades de regulação e de intervenção que permitam:

- a recriação da escola como espaço público de decisão colectiva, baseada numa nova concepção de cidadania que, como diz Whitty, "vise criar a unidade sem negar a diversidade"; 
- que o Estado continue a assegurar, como lhe compete, a "manutenção da escola num espaço de justificação política" (Derouet, 2003), sem que isso signifique ser o Estado o detentor único da legitimidade dessa justificação.

É este o grande desafio que se coloca a todos os que continuam a acreditar na necessidade de provermos colectivamente um serviço público que garanta o pleno direito à educação e o acesso a uma cultura comum, para todas as crianças e jovens, em condições de equidade, de igualdade de oportunidades e de justiça social.

Neste sentido, a "defesa da escola pública" passa, por um lado, em desmontar o carácter pretensamente "neutro" da introdução de uma lógica de mercado na educação, denunciando a sua "ética" perversa e a sua intencionalidade política e, por outro, fazer da definição e regulação das políticas educativas um processo de construção colectiva do bem comum que à educação cabe oferecer, em condiçôes de igualdade e justiça social, a todos os cidadãos.

Por tudo quanto foi dito, podemos concluir que a repolitização da educação, a multiplicação das instâncias e momentos de decisão, a diversificação das formas de associação no interior dos espaços públicos e o envolvimento de um maior número de actores conferem ao sistema de regulação da educação uma complexidade crescente. Esta complexidade exige um papel renovado para a acção do Estado, com o fim de compatibilizar o desejável respeito pela diversidade e individualidade dos cidadãos, com a prossecução de fins comuns necessários à sobrevivência da sociedade - de que a educação é um instrumento essencial.

Essa compatibilização só é possível com o reforço das formas democráticas de participação e decisão, o que, nas sociedades contemporâneas, exige cada vez mais uma qualificada e ampla informação, a difusão de instâncias locais e intermédias de decisão, uma plena inclusão de todos os cidadãos (particularmente dos que até aqui têm sido sistematicamente excluídos, do interior e do exterior). Só assim é possível "estabelecer um acordo sobre uma base comum suficientemente generosa, atractiva e plausível que possa unificar os cidadãos no apoio à escola pública" e que Tyack \& Cuban (1995, p. 142) consideram ser "uma necessidade crucial do nosso tempo".

Recebido em julho de 2005 e aprovado em agosto de 2005. 
O estado, a educação e a regulação das políticas públicas

\section{Notas}

1. Citado por Demailly (2001) que aplica esta distinção à análise da avaliação como sistema de regulação.

2. O projecto Reguleducnetwork foi subsidiado pela Comissão Europeia, no âmbito do programa "Improving the Socio-economic Knowledge Base" e os seus relatórios parcelares e final podem ser consultados em <www.fpce.ul.ptlcentroslceescola > ou em <www.girsef.ucl.ac.be/ europeanproject.htm>. Nos números 82 e 84 da revista Educação \& Sociedade, foram publicados dois artigos com resultados parcelares deste projecto (Barroso, 2003b; Barroso \& Viseu, 2003).

3. A apresentação destes resultados baseia-se no relatório final do projecto coordenado por Christian Maroy (2004) e que se encontra disponível em <www.girsef.ucl.ac.be/europeanproject.htm>

\section{Referências bibliográficas:}

AFONSO, N. A regulação da educação na Europa: do Estado educador ao controlo social da escola pública. In: BARROSO, J. (Org.). A escola pública: regulação, desregulação, privatização. Porto: ASA, 2003. p. 49-78.

BALL, S. Reforming schools/reforming teaches and the terrors of performativity. In: CONGRESSO LUSO-BRASILEIRO DE POLITICA E ADMINISTRAÇÃO DA EDUCAÇÃO, 2., 2001, Braga. Politica e administração da educaçãao: investigação, formação e práticas. Braga: Universidade do Minho; Centro de Investigação em Educação, 2001. (CD-ROM)

BARROSO, J. Autonomie et modes de régulation locale dans le système éducatif. Revue Française de Pédagogie, Paris, n. 130, p. 57-71, jan./mar. 2000 .

BARROSO, J. Gestão local da educação: entre o Estado e o mercado, a responsabilização colectiva. In: Machado, L.; FerReIRA, N. (Org.). Polititca e gestão da educação: dois olhares. Rio de Janeiro: DP\&A; ANPAE, 2002. p. 173-197.

BARROSO, J. (Org.). A escola pública: regulação, desregulação, privatização. Porto: ASA, 2003.

BARROSO, J. A "escolha da escola" como processo de regulação: integração ou selecção social. In: BARROSO, J. (Org.). A escola pública: regulação, desregulação, privatização. Porto: ASA, 2003. p. 79-109.

BARROSO, J. Organização e regulação dos ensinos básico e secundário, 
em Portugal: sentidos de uma evolução. Educação \& Sociedade, Campinas, v. 24, n. 82, p. 63-92, 2003.

BARROSO, J. Escola da Ponte: defender, debater e promover a escola pública. In: Canário, R.; Matos, F.; Trindade, R. (Org.). Escola da Ponte: defender a escola pública. Porto: Profediçoes, 2004. p. 11-25.

BARROSO, J. Os novos modos de regulação das políticas educativas na Europa: da regulação do sistema a um sistema de regulações. Educação em Revista, Belo Horizonte, n. 39, p. 19-28, jul. 2004.

BARROSO, J. Les nouveaux modes de régulation des politiques éducatives en Europe : de la régulation du système à un système de régulations. In: DutercQ, Y. (Dir.). Les régulations des politiques d'éducation. Rennes: Presses Universitaires de Rennes, 2005. p. 151-171.

BARROSO, J.; VISEU, S. A emergência de um mercado educativo no planeamento da rede escolar: de uma regulação pela oferta a uma regulação pela procura. Educação \& Sociedade, Campinas, v. 24, n. 84, p. 897921, 2003.

BAUBY, P. L'Europe des services publics: entre libéralisation, modernisation, régulation, évaluation. Politique et Management Public, n. 1, p. $15,2002$.

BETTENCOURT, M.B. L'évaluation des établissements d'enseignement en tant que mode de régulation. Une étude de cas en enseignement collégial. 2004. 302f. Tese (Doutorado) - Faculté des Études Supérieurs, Université de Montréal, Montréal.

BOYER, R. L'aprés-consensus de Washington: institutionnaliste et systémique?. In: ASSOCIATION RECHERCHE ET REGULATION. L'année de la régulation: economie, institutions, pouvoirs, n. 5, 2001-2002. Paris: Presses de Sciences PO, 2001. p. 13-56.

CANARIO, R. Escola: crise ou mutação. In: Prost, A. et al. Espaços de educação tempos de formação. Lisboa: Fundação Calouste Gulbenkian, 2002. p. 141-151.

COMMISSION DES COMMUNAUTES EUROPEENNES. Livre vert sur les services d'intérêt général: COM(2003) 270 final. Bruxelles, 2003. (mimeo.). 
O estado, a educação e a regulação das políticas públicas

CROZIER, M.; FRIEDBERG, E. L'acteur et le système. Paris: Seuil, 1977.

DEMAILLY L. Enjeux de l'évaluation et régulation des systèmes scolaires. In: Demailly L. (Ed.). Évaluer les politiques éducatives. Bruxelles: DeBoeck Université, 2001. p. 13-30.

DEROUET, J.-L. L'avenir d'une illusion ou Comment refonder le projet du collège unique dans une société postmoderne. In: Derouet, J.-L. (Dir.). Le collège unique en question. Paris: PUF, 2003. p. 1-28.

DIEBOLT, C. Education, système et régulation. In: JOURNEES D'ETUDES LA REGULATION DU SYSTEME EDUCATIF, Fondation Nationale des Sciences Politiques, 2001, Paris. Disponível em: <www.u-bourgogne.fr/IREDU > Acesso em: 18 abr. 2003.

FUKUYAMA, F. State building: gouvernance et ordre du monde au XXI siècle. Paris: La Table Ronde, 2004. (Traduzido da edição americana).

GINTIS, H. The political economy of school choice. Teachers College Record, New York, v. 96, n. 3, p. 10-11, 1995.

LESSARD, C.; BRASSARD, A.; LUSIGNAN, J. Les tendances des politiques éducatives en matière de structures et de régulation, d'imputabilité et de reddition de comptes: les cas du Canada (Ontario et Colombie-Britannique), de la France et du Royaume-Uni. Montréal: LABRIProf-CrifPe, Faculté des Sciences de l'Education, Université de Montréal, 2002.

MAROY, C.; DUPRIEZ, V. La régulation dans les systèmes scolaires: proposition théorique et analyse du cadre structurel en Belgique francophone. Revue Française de Pédagogie, Paris, n. 130, p. 73-87, jan/mar. 2000 .

MAROY, C. Regulations and inequalities in European Education Systems: final report. Bruxelles, 2004. Disponível em: <http://www.girsef.ucl.ac.be/ europeanproject.htm>.

MEHEL, L. Phénomène administratif et phénomène éducatif. In: AAVV Formation 2. Administration, langage et formation. Paris: Petite Bibliothèque Payot, 1974. p. 11-69.

NOVOA, A. Histoire \& comparaison: essais sur l'educatio. Lisboa: EDUCA, 1998. 
PIAGET, J. L'épistémologie des régulations. In: GAdoffre, G.; Lichnerowicz, A; Perroux, F. (Ed.). L'idée de régulation dans les sciences. Paris: Maloine-Doin, 1977. p. I-XIII.

REYNAUD, J.-D. Les règles du jeu : l'action collective et la régulation sociale. 3. ed. Paris: A. Colin, 1997.

REYNAUD, J.-D. Régulation de contrôle, régulation autonome, régulation conjointe. In: TERSSAC, G. (Dir.). La théorie de la régulation sociale de Jean-Daniel Reynaud: débats et prolongements. Paris: La Decouverte, 2003. p. 103-113.

ROSNAY, J. Le macroscope: vers une vision globale. Paris: Seuil, 1975.

TYACK, D.; CUBAN, L. Tinkering toward utopia: a century of public school reform. Cambridge, Mass.: Harvard University, 1995.

WHITTY, G. Making sense of education policy. London: Paul Chapman, 2002. 